\title{
Sleep apnoea and incident malignancy in type 2 diabetes
}

\author{
Sarah Driendl ${ }^{1,9}$, Michael Arzt ${ }^{1,9}$, Claudia S. Zimmermann², Bettina Jung ${ }^{3,4}$, \\ Tobias Pukrop ${ }^{5}$, Carsten A. Böger ${ }^{3,4}$, Sebastian Haferkamp ${ }^{6}$, Florian Zeman ${ }^{7}$, \\ Iris M. Heid ${ }^{8}$ and Stefan Stadler ${ }^{1}$
}

Affiliations: ${ }^{1}$ Dept of Internal Medicine II, University Hospital Regensburg, Regensburg, Germany. ${ }^{2}$ Dept of Internal Medicine I, University Hospital Regensburg, Regensburg, Germany. ${ }^{3}$ Dept of Nephrology, University Hospital Regensburg, Regensburg, Germany. ${ }^{4}$ Dept of Nephrology, Traunstein, Germany. ${ }^{5}$ Dept of Internal Medicine III, University Hospital Regensburg, Regensburg. Germany. ${ }^{6}$ Dept of Dermatology, University Hospital Regensburg, Regensburg, Germany. ${ }^{7}$ Centre of Clinical Studies, University Hospital Regensburg, Regensburg, Germany. ${ }^{8}$ Dept of Genetic Epidemiology, University Hospital Regensburg, Regensburg, Germany. ${ }^{9}$ These authors contributed equally.

Correspondence: Stefan Stadler, Dept of Internal Medicine II, University Medical Center Regensburg, FranzJosef-Strauss-Allee 11, 93055 Regensburg, Germany. E-mail: stefan.stadlerवukr.de

\section{ABSTRACT}

Background: Sleep apnoea and type 2 diabetes (T2D) have been linked to malignancy. The aim of the present study was to evaluate the association between sleep apnoea and incidence of malignancy in patients with T2D.

Methods: The DIACORE (DIAbetes COhoRtE) study is a prospective, population-based cohort study in T2D patients. In the sleep disordered breathing substudy, the apnoea-hypopnoea index (AHI), oxygen desaturation index (ODI) and percentage of night-time spent with a peripheral oxygen saturation of $<90 \%$ $\left(t_{\text {sat90\% }}\right)$ were assessed using a two-channel ambulatory monitoring device. Malignancy diagnoses were gathered using self-reported medical history data validated by medical records. Hazard ratios (HRs) for incident malignancy were derived by Cox regression adjusting for sex, age, body mass index, smoking status, alcohol intake, socioeconomic status and HbA1c.

Results: Of 1239 patients with T2D (mean age 67 years, $41 \%$ female, mean body mass index $30.9 \mathrm{~kg} \cdot \mathrm{m}^{-2}$ ), 79 (6.4\%) were first-time diagnosed with a malignancy within a median follow-up period of 2.7 years

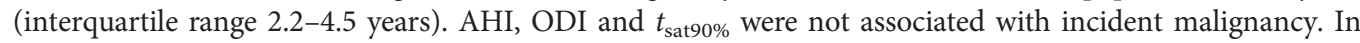
subgroup analysis, females showed increased cancer risk per AHI unit (adjusted HR 1.03 per AHI unit, 95\% CI 1.00-1.06; $\mathrm{p}=0.028$ ) and severe sleep apnoea (defined as AHI $\geqslant 30$ events $^{-1}{ }^{-1}$; adjusted HR 4.19, 95\% CI 1.39-12.77; $\mathrm{p}=0.012$ ). This was not seen in males, and a significant interaction was observed (interaction terms $\mathrm{p}=0.048$ and $\mathrm{p}=0.033$, respectively).

Conclusion: Sleep apnoea was not associated with incident malignancy in T2D patients. However, stratified analysis revealed a significant association between sleep apnoea and incident malignancy in females, but not in males.

@ERSpublications

In patients with type 2 diabetes, sleep apnoea is not associated with the incidence of malignancy. However, stratified analysis shows that sleep apnoea is associated with incident malignancy in females, but not in males. https://bit.ly/37RAK8V

Cite this article as: Driendl S, Arzt M, Zimmermann CS, et al. Sleep apnoea and incident malignancy in type 2 diabetes. ERJ Open Res 2021; 7: 00036-2021 [https://doi.org/10.1183/ 23120541.00036-2021].

This article has supplementary material available from openres.ersjournals.com

Received: 17 Jan 2021 | Accepted: 7 Feb 2021

Copyright $\odot$ The authors 2021. This version is distributed under the terms of the Creative Commons Attribution NonCommercial Licence 4.0. For commercial reproduction rights and permissions contact permissions@ersnet.org 


\section{Introduction}

Sleep apnoea is a highly prevalent disorder characterised by repetitive apnoeas and hypopnoeas and arousals from sleep. The prevalence of moderate-to-severe sleep apnoea (defined as apnoea-hypopnoea index $(\mathrm{AHI}) \geqslant 15$ events $\cdot \mathrm{h}^{-1}$ ) is up to $49 \%$ in males and $23 \%$ in females, and it has increased substantially over the past two decades $[1,2]$. Sleep apnoea is strongly associated with cardiovascular and metabolic morbidity and mortality [3,4]. Sleep apnoea leads to intermittent hypoxaemia and sleep fragmentation, and causes sympathetic nervous system activation, oxidative stress and systemic inflammation [5-8]. Sleep apnoea and intermittent hypoxaemia have been linked to an increased incidence [9-12], growth, angiogenesis, chemoresistance and radioresistance in tumours [13-16]. Experimental studies have shown that intermittent hypoxaemia can lead to a faster and more invasive tumour growth as well as metastasis in animal studies [17-19]. There was an association between sleep apnoea and increased tumour mortality in clinical studies [20]. Until now, clinical studies investigating the association between sleep apnoea and incidence of malignancy have shown inconsistent results [21,22]. When such evidence is documented in cohort studies where incident cancer is assessed, this could point to new paths of cancer prevention through early diagnosis and treatment of sleep apnoea or nocturnal hypoxaemia.

Type 2 diabetes mellitus (T2D) is an important hazard, with prevalence rates rising worldwide [23, 24]. T2D and sleep apnoea are each likely to contribute to the development of the other [25] and show high co-occurrence rates [26-29]. T2D has also been linked to an increased risk of incident malignancies [30]. This is the first study to evaluate the association between sleep apnoea and incidence of malignancy in a sample of patients with T2D.

\section{Methods}

\section{Study design}

The investigated patients were participants of the DIACORE (DIAbetes COhoRtE)-SDB (sleep disordered breathing) substudy [31]. DIACORE is a two-centre prospective and longitudinal cohort study of T2D patients of European descent [32]. The DIACORE study was originally designed to determine incident micro- and macrovascular T2D complications, malignancy and hospitalisation [32]. As the substudy was conducted only at the Regensburg Clinical Study Centre (Regensburg, Germany), all participants from the Regensburg centre were invited to take part in the DIACORE-SDB substudy. 492 (16\%) patients did not agree to participate. Other patients did not participate for the following reasons: recruiting centre not offering SDB monitoring, current use of positive airway pressure (PAP) therapy, study termination and SDB monitoring not performed (figure 1).

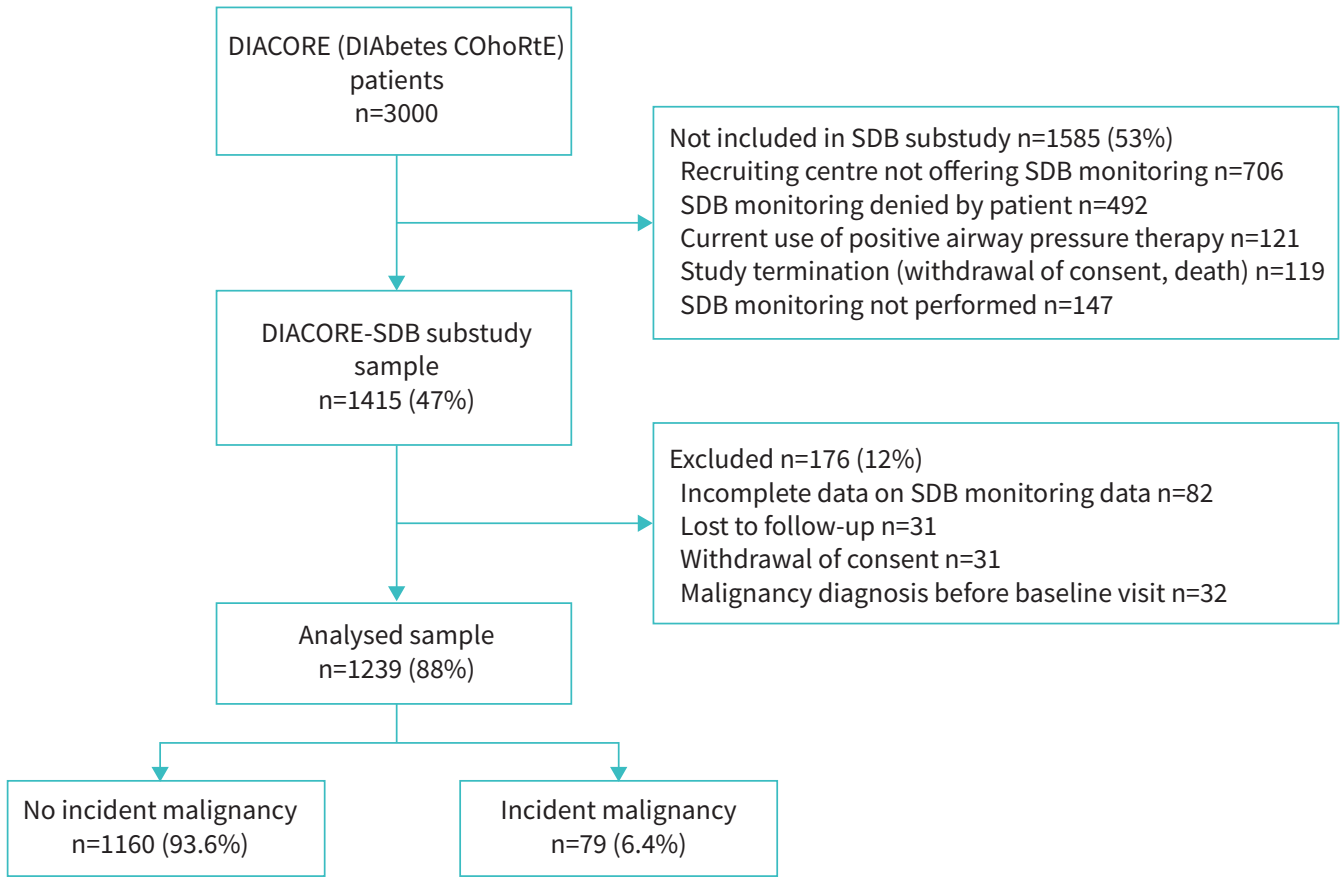

FIGURE 1 Study flow chart. SDB: sleep disordered breathing. 
The participants were subjected to a standardised online questionnaire, blood sampling and physical examination, and were invited to re-examinations every 2 years. Assessment of sleep apnoea was performed using a two-channel ambulatory monitoring device (ApneaLink; ResMed, Sydney, Australia). The DIACORE-SDB substudy started in November 2011 and patients were followed-up every 2 years until April 2018.

The protocol, data protection strategy and study procedures were approved by the ethics committees of the participating institutions and in accordance with the Declaration of Helsinki. Patients participated in the DIACORE study only after providing written consent. The study protocol has been described previously [32]. The study is registered at the German Clinical Trials Register (https://drks.de/; identifier number DRKS00010498) and at the International Clinical Trials Registry Platform of the World Health Organization.

\section{Study population}

All T2D patients living in the regions around Regensburg and Speyer were eligible for participation in the DIACORE study (figure 1) [32]. The recruitment process has been described previously [32]. Further inclusion criteria were as follows: ability to fully understand the study information; ability to give written informed consent; age $\geqslant 18$ years; and self-reported Caucasian ethnicity [32]. Exclusion criteria included a history of active malignancy within the past 5 years (prostatic cancer within the past 2 years); haemochromatosis; history of pancreoprivic or self-reported type 1 diabetes mellitus; acute infection or fever; pregnancy; chronic viral hepatitis or HIV infection; presence of autoimmune disease potentially affecting kidney function; and chronic renal replacement therapy [32]. For the DIACORE-SDB substudy, participants were included if they consented to perform sleep apnoea monitoring and excluded if they currently used PAP therapy [31].

Alcohol intake (number of drinks per week), smoking status (current, former or never), socioeconomic status (according to the Robert Koch Institute, Germany [33], subdivided into four groups ranging from 1 (lowest) to 4 (highest) and including educational level, professional qualification and income) and physical activity (defined as light activity at least three times per week) were evaluated by standardised questionnaires. Subjective daytime sleepiness was assessed using the validated Epworth Sleepiness Scale. Patients were asked to rank how likely it was for them to fall asleep in various common situations [31]. Scores range from 0 (least sleepy) to 24 (sleepiest). Excessive daytime sleepiness is defined as a score of $\geqslant 11$.

\section{Assessment of sleep apnoea}

Ambulatory sleep apnoea monitoring was conducted using a validated device $[34,35]$ (ApneaLink), as described previously [31]. The participants were instructed on the use of the device by trained personnel in a standardised manner [31]. Nasal flow and pulse oximetry were measured. AHI was calculated as the mean number of apnoea and hypopnoea events per hour of recording time. Oxygen desaturation index (ODI) measured the mean number of respiratory events per hour where blood oxygen level dropped by $4 \%$ in comparison with immediately preceding basal value. The percentage of the total recording time with a peripheral oxygen saturation below $90 \%\left(t_{\text {sat90\% }}\right)$ was documented. The standard settings of the monitoring device were used for the definitions of apnoea, hypopnoea and desaturation [36]. Due to the lack of a chest band, it was not possible to differentiate between obstructive and central apnoea.

All patients were informed about the results of sleep apnoea monitoring, but further diagnosis and treatment was not part of the protocol of DIACORE. Use of PAP treatment during follow-up was evaluated by standardised questionnaires as part of the protocol of DIACORE. PAP treatment status was available in 1133 patients.

\section{Assessment of incident malignancy}

The incidence of a malignancy, defined as the first diagnosis of a malignant neoplasm at any time between the sleep apnoea monitoring (starting November 2011) and the last performed DIACORE follow-up visit (April 2018), was assessed by medical history and medical records at every visit by the DIACORE end-point committee [32]. Medical documentation was requested up to three times from the patients' treating physicians and validated by an experienced physician. If a patient-reported end-point could not be confirmed by available documentation or if adequate medical documentation was not available, then that end-point was coded as "not validated" and analysed as "no cancer" [32]. Basal cell carcinomas were excluded from the analysis, as these tumours rarely metastasise and have low mortality.

\section{Statistical analysis}

Descriptive data are presented as mean \pm SD for normally distributed variables and as median and interquartile range for non-normally distributed variables. Continuous variables were compared by t-test 


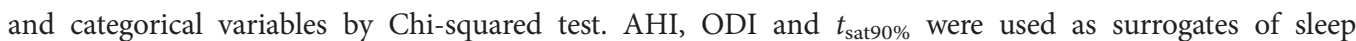
apnoea severity, all as continuous variables and in categories. Sleep apnoea severity categories according to the AHI were defined as $<5$ events $\cdot h^{-1}$, no sleep apnoea; 5-<15 events. $h^{-1}$, mild sleep apnoea; $15-<30$ events $\cdot h^{-1}$, moderate sleep apnoea; and $\geqslant 30$ events $\cdot h^{-1}$, severe sleep apnoea. As there is no clinically established cut-off, $t_{\text {sat } 90 \%}$ was dichotomised by the median. Cox proportional hazard regression models were used to analyse the association between sleep apnoea parameters as well as for severe sleep apnoea and the incidence of malignancy. Known risk factors for cancer development such as age, sex, body mass index (BMI), smoking status, alcohol intake and socioeconomic status were included as covariates, as well as HbA1c as a surrogate of T2D severity. Sex- and age-specific associations between sleep apnoea and incidence of malignancy were analysed. The results are presented as hazard ratios (HR) with 95\% confidence intervals. Cumulative hazards of the multivariable analyses were analysed and visualised in figures. p-values $<0.05$ were considered significant, except in the subgroup analyses by sex and high versus low age, where we performed a Bonferroni correction for two independent tests and used a stricter level of significance, i.e. $\mathrm{p}<0.05 / 2=0.025$. Data were analysed using the SPSS statistical software package (SPSS 25.0; IBM SPSS Statistics, Armonk, NY, USA).

\section{Results}

\section{Patient characteristics}

Of the 1415 patients monitored for sleep apnoea, 176 (12.4\%) could not be included in the final analysis due to incomplete polygraphy data, loss to follow-up, withdrawal of consent or history of cancer at baseline assessment (figure 1). Of the analysed sample $(n=1239), 292$ (23.3\%) patients had no sleep apnoea, 521 (42.1\%) had mild sleep apnoea, 298 (24.1\%) had moderate sleep apnoea and 128 (10.3\%) had severe sleep apnoea. Patients with severe sleep apnoea were predominantly male, significantly more likely to be obese and exhibited a significantly higher $t_{\text {sat90\% (table 1). The median (interquartile range) }}$ follow-up time was $2.7(2.2-4.5)$ years.

\section{Sleep apnoea and incidence of malignancy}

During the observation period, $79(6.4 \%)$ patients received the diagnosis of an incident malignant tumour. The most frequent diagnoses were skin tumours, followed by prostate cancer, colorectal carcinoma and pancreatic cancer (table 2).

Sleep apnoea was described using event-driven parameters (such as AHI and ODI) as well as with measures of cyclic and noncyclic nocturnal hypoxaemia $\left(t_{\text {sat } 90 \%}\right)$. The rates of incident malignancies were $6.3 \%, 5.4 \%$ and $9.4 \%$ in the groups of no or mild, moderate and severe sleep apnoea (Chi-squared test

\section{TABLE 1 Baseline characteristics of the 1239 patients overall and according to severity of} sleep disordered breathing

\begin{tabular}{|c|c|c|c|}
\hline & Entire cohort & $\mathrm{AHI}<30$ events $\cdot \mathrm{h}^{-1}$ & $A H I \geqslant 30$ events $\cdot h^{-1}$ \\
\hline Patients & 1239 & $1111(89.7)$ & 128 (10.3) \\
\hline Age years & $67 \pm 9$ & $66 \pm 9$ & $68 \pm 8$ \\
\hline Female & $511(41.2)$ & $482(43.4)$ & 29 (22.7) \\
\hline BMI $\mathbf{k g} \cdot \mathrm{m}^{-2}$ & $30.9 \pm 5.3$ & $30.5 \pm 5.2$ & $33.6 \pm 5.9$ \\
\hline Waist-hip ratio & $0.95 \pm 0.08$ & $0.95 \pm 0.08$ & $1.00 \pm 0.08$ \\
\hline Obesity & $622(50.2)$ & $533(48.0)$ & 89 (69.5) \\
\hline $\mathrm{HbA} 1 \mathrm{c} \mathrm{mmol} \cdot \mathrm{mol}^{-1}$ & $51 \pm 11$ & $51 \pm 12$ & $50 \pm 9$ \\
\hline Former or current smokers & $701(56.6)$ & $624(56.2)$ & $77(60.2)$ \\
\hline High alcohol intake & $353(28.5)$ & $309(27.8)$ & $44(34.4)$ \\
\hline Socioeconomic status $\pi$ & $2(1-2)$ & $2(1-2)$ & $2(2-2)$ \\
\hline Physical inactivity $^{+}$ & $699(56.4)$ & $620(55.8)$ & 79 (61.7) \\
\hline Follow-up time years & $2.7(2.2-4.5)$ & $2.8(2.2-4.5)$ & $2.4(2.1-4.5)$ \\
\hline Excessive daytime sleepiness ${ }^{\S}$ & $87(7.1)$ & $77(7.0)$ & $10(7.8)$ \\
\hline AHI events- $h^{-1}$ & $10(5-19)$ & $9(4-15)$ & $44(36-52)$ \\
\hline ODI events $\cdot \mathrm{h}^{-1}$ & $9(5-19)$ & $8(5-15)$ & $39(33-49)$ \\
\hline$t_{\text {sat90\% }}$ & $10.4(2.5-30.6)$ & $8.8(2.1-28.4)$ & $23.5(13.7-45.4)$ \\
\hline \multicolumn{4}{|c|}{$\begin{array}{l}\text { Data are presented as } \mathrm{n} \text {, mean } \pm \mathrm{SD}, \mathrm{n}(\%) \text { or median (interquartile range). AHI: apnoea-hypopnoea index; } \\
\text { BMI: body mass index; ODI: oxygen-desaturation index; } t_{\text {sat } 90 \%} \text { : percentage of night-time spent with oxygen } \\
\text { saturation }<90 \% .{ }^{\#}: \geqslant 3 \text { drinks per week; }{ }^{\text {ๆ }} \text { : according to Robert Koch Institute (Germany) [37] subdivided } \\
\text { into four groups ranging from } 1 \text { (lowest) to } 4 \text { (highest) and including educational level, professional } \\
\text { qualification and income; }{ }^{+} \text {: light activity } \leqslant 2 \text { times per week; }{ }^{\S} \text { : Epworth Sleepiness Scale } \geqslant 11 \text {. }\end{array}$} \\
\hline
\end{tabular}




\begin{tabular}{|c|c|}
\hline Total sample & 1239 \\
\hline Skin tumours ${ }^{\#}$ & 20 (25.3) \\
\hline Prostate carcinoma & 9 (11.5) \\
\hline Colorectal carcinoma & $7(8.9)$ \\
\hline Pancreatic carcinoma & 7 (8.9) \\
\hline Breast cancer & $5(6.3)$ \\
\hline Pulmonary carcinoma & $5(6.3)$ \\
\hline Malignancy of the haematopoietic and lymphatic system & $5(6.3)$ \\
\hline Malignancy of the female genital organ & $5(6.3)$ \\
\hline Malignancy of the urinary organ & $5(6.3)$ \\
\hline Others" & 11 (13.9) \\
\hline Total & 79 (100) \\
\hline Males & 728 \\
\hline Skin tumours ${ }^{\#}$ & 15 (28.3) \\
\hline Prostate carcinoma & $9(17.0)$ \\
\hline Colorectal carcinoma & $7(13.2)$ \\
\hline Malignancy of the urinary organ & $5(9.4)$ \\
\hline Pulmonary carcinoma & $4(7.5)$ \\
\hline Pancreatic carcinoma & $3(5.7)$ \\
\hline Malignancy of the haematopoietic and lymphatic system & $2(3.8)$ \\
\hline Others" & $8(15.1)$ \\
\hline Total & $53(100)$ \\
\hline Females & 511 \\
\hline Skin tumours $\#$ & $5(19.2)$ \\
\hline Breast cancer & 5 (19.2) \\
\hline Malignancy of the female genital organ & $5(19.2)$ \\
\hline Pancreatic carcinoma & $4(15.4)$ \\
\hline Malignancy of the haematopoietic and lymphatic system & $3(11.6)$ \\
\hline Pulmonary carcinoma & $1(3.8)$ \\
\hline Others & $3(11.6)$ \\
\hline Total & $26(100)$ \\
\hline \multicolumn{2}{|c|}{$\begin{array}{l}\text { Data are presented as } \mathrm{n} \text { or } \mathrm{n}(\%) .{ }^{\#} \text { : malignant melanomas, squamous cell carcinomas and lentiginous } \\
\text { melanomas (basal cell carcinomas were excluded); " : cancer types observed only in few or single persons, } \\
\text { e.g. liver tumour, parotid tumour, meningioma. }\end{array}$} \\
\hline
\end{tabular}

$\mathrm{p}=0.294$ ), respectively. Hazard ratios for the incidence of a malignancy in dependency on continuous and dichotomised sleep apnoea parameters are given in tables 3 and 4; all analyses were adjusted for potential confounders such as age, sex, BMI, smoking status, alcohol intake, socioeconomic status and HbA1c. There was no association between any of the six sleep apnoea parameters and incident cancer in the entire

TABLE 3 Adjusted hazard ratios (HRs) for the incidence of malignancy in 1239 patients with type 2 diabetes during a median follow-up of 2.7 years (number of events 79)

\begin{tabular}{|c|c|c|}
\hline & Adjusted HR $\left(95 \% \mathrm{Cl}^{\#}\right.$ & p-value \\
\hline \multicolumn{3}{|l|}{$A H I$ events $\cdot h^{-1}$} \\
\hline AHI (continuous) & $1.01(0.99-1.03)$ & 0.416 \\
\hline $\mathrm{AHI} \geqslant 30$ & $1.30(0.64-2.62)$ & 0.473 \\
\hline \multicolumn{3}{|l|}{ ODI events $\cdot \mathrm{h}^{-1}$} \\
\hline ODI (continuous) & $1.00(0.98-1.02)$ & 0.799 \\
\hline$O D I \geqslant 30$ & $1.24(0.57-2.68)$ & 0.584 \\
\hline \multicolumn{3}{|l|}{$t_{\text {sat90\% }}$} \\
\hline$t_{\text {sat } 90 \%}$ (continuous) & $1.00(1.00-1.01)$ & 0.395 \\
\hline$t_{\text {sat } 90 \%} \geqslant 10.4 \%$ & $1.59(0.94-2.68)$ & 0.085 \\
\hline \multicolumn{3}{|c|}{$\begin{array}{l}\text { HRs calculated using Cox proportional hazards regression analysis. The multivariable analyses were } \\
\text { adjusted for sex, age, body mass index, smoking status, alcohol intake, socioeconomic status and HbA1c. } \\
\text { AHI: apnoea-hypopnoea index; ODI: oxygen desaturation index; } t_{\text {sat } 90 \% \text { : percentage of night-time spent with }} \\
\text { oxygen saturation }<90 \% \text {. }\end{array}$} \\
\hline
\end{tabular}


TABLE 4 Adjusted hazard ratios (HRs) for the incidence of malignancy in 1239 patients with type 2 diabetes during a median follow-up of 2.7 years stratified by sex and age

\begin{tabular}{|c|c|c|c|c|c|c|c|c|}
\hline & \multicolumn{2}{|l|}{ Males } & \multicolumn{2}{|c|}{ Females } & \multicolumn{2}{|c|}{$\geqslant 70$ years } & \multicolumn{2}{|c|}{$<70$ years } \\
\hline Events $\mathrm{n}$ & 53 & & 26 & & 43 & & 36 & \\
\hline \multicolumn{9}{|l|}{ AHI events $\cdot h^{-1}$} \\
\hline AHI (continuous) & $1.00(0.97-1.02)$ & 0.659 & $1.03(1.00-1.06)$ & 0.028 & $1.00(0.98-1.03)$ & 0.751 & $1.01(0.98-1.03)$ & 0.538 \\
\hline ODI (continuous) & $0.99(0.96-1.01)$ & 0.357 & $1.04(1.00-1.07)$ & 0.032 & $1.00(0.97-1.03)$ & 0.933 & $1.00(0.97-1.03)$ & 0.972 \\
\hline $\mathrm{ODI} \geqslant 30$ & $0.62(0.22-1.79)$ & 0.380 & $5.64(1.78-17.90)$ & 0.003 & $1.34(0.53-3.36)$ & 0.539 & $0.88(0.20-3.83)$ & 0.863 \\
\hline \multicolumn{9}{|l|}{$t_{\text {sat } 90 \%}$} \\
\hline$t_{\text {sat9 } 90 \%}$ (continuous) & $1.00(0.99-1.01)$ & 0.670 & $1.02(1.00-1.03)$ & 0.035 & $1.00(0.99-1.01)$ & 0.912 & $1.01(1.00-1.02)$ & 0.236 \\
\hline$t_{\text {sat9 } 90 \%} \geqslant 10.4 \%$ & $1.28(0.66-2.46)$ & 0.467 & $2.57(1.03-6.41)$ & 0.043 & $0.91(0.51-2.11)$ & 0.913 & $2.43(1.09-5.42)$ & 0.030 \\
\hline
\end{tabular}

HRs calculated by Cox proportional hazards regression analysis. The multivariable analyses were adjusted for sex, age, body mass index, smoking status, alcohol intake, socioeconomic status and HbA1c. AHI: apnoea-hypopnoea index; ODI: oxygen desaturation index; $t_{\text {sat } 90 \%}$ : percentage of night-time spent with oxygen saturation $<90 \%$.

cohort (table 3). For patients with severe sleep apnoea there was no significantly elevated cumulative hazard (figure 2).

In subanalyses, we stratified the data by sex and high versus low age ( $\geqslant 70$ years versus $<70$ years). In females, all six sleep apnoea parameters were associated with incident malignancy: continuous AHI, ODI

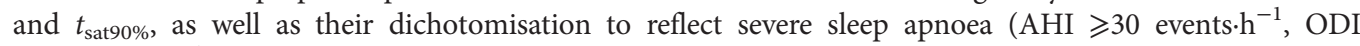
$\geqslant 30$ events $\cdot \mathrm{h}^{-1}$ or $t_{\text {sat } 90 \%}$ above the median of $10.4 \%$ ) (table 4 , figure 3 ). Severe sleep apnoea (defined as AHI $\geqslant 30$ events $\cdot h^{-1}$ or ODI $\geqslant 30$ events $\cdot h^{-1}$ ) was significantly associated with incident malignancy on a Bonferroni-corrected significance level of $0.05 / 2=0.025$. Still, the other parameters showed consistent results (table 4). The hazard ratio estimates for severe sleep apnoea ranged from 2.57 to 4.19 and thus indicated a substantially increased risk of incident malignancy.

No association between the severity of sleep apnoea or severe sleep apnoea with incident malignancy was found in males (table 4, figure 3). The associations were significantly different between females and males for most parameters: continuous AHI (interaction term 0.049), AHI $\geqslant 30$ events. $\mathrm{h}^{-1}$ (interaction term 0.033 ) and ODI $\geqslant 30$ events. $\mathrm{h}^{-1}$ (interaction term 0.009), but not for continuous ODI (interaction

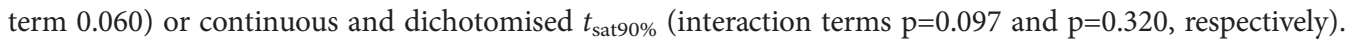

When HbAlc was treated as an effect modifier and the cohort was stratified by HbA1c (HbA1c $<6.5 \%$ versus $\mathrm{HbA} 1 \mathrm{c} \geqslant 6.5 \%)$, there was no significant difference between the groups regarding the association between sleep apnoea and the incidence of malignancy.

In the subgroup analyses by high versus low age with the cut-off at 70 years, we found no significant association of any of the six parameters at the significance level of $0.05 / 2=0.025$ (table 4 ). When including an interaction term, we found no significantly different association between the groups of patients aged $\geqslant 70$ years versus $<70$ years.

In the present study, there were no associations between the mean and minimal peripheral oxygen saturation, excessive daytime sleepiness, daytime napping, duration of night's sleep or sleep efficiency (hours of sleep per hours in bed) and the incidence of a malignancy ( $p$-values ranging from 0.090 to 0.993 ).

\section{PAP treatment and incidence of malignancy}

During follow-up, 74 patients initiated PAP treatment within their clinical routine, of whom 30 had severe sleep apnoea. Of the 72 patients with newly started PAP therapy who had at least mild sleep apnoea at DIACORE-SDB monitoring, $6.9 \%$ had an incident malignancy compared to $5.3 \%$ of the 799 patients with at least mild sleep apnoea without PAP treatment.

\section{Discussion}

In this prospective cohort study of T2D patients, we investigated the association between sleep apnoea and the incidence of malignancy. Sleep apnoea at baseline was not significantly associated with the incidence 


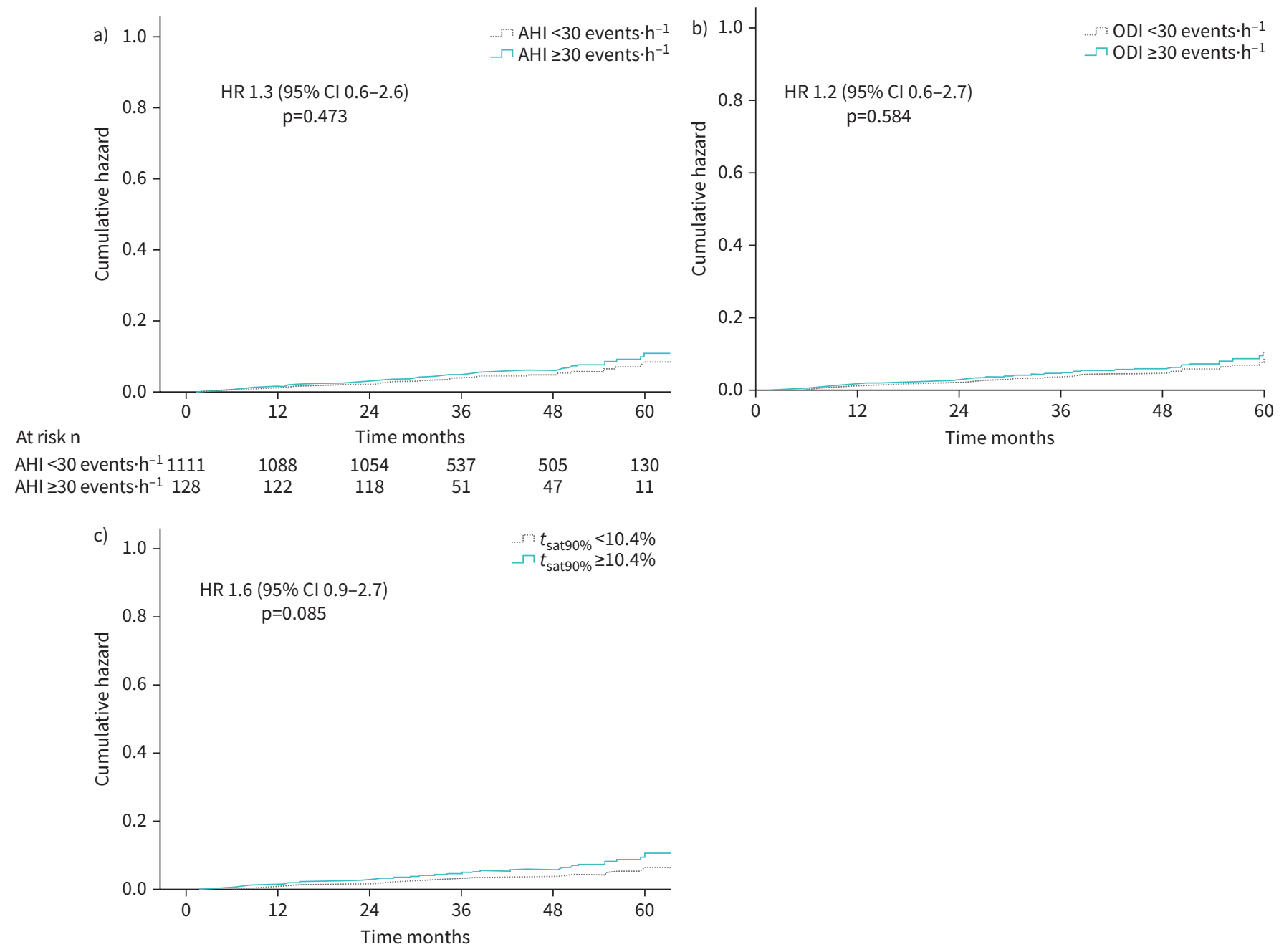

FIGURE 2 Cumulative adjusted hazard for incident malignancy in 1239 patients with diabetes mellitus type 2 and a) apnoea-hypopnoea index (AHI) $<30$ events $\cdot h^{-1}$ versus $\geqslant 30$ events $\cdot h^{-1}$; b) oxygen desaturation index (ODI) $<30$ events $\cdot h^{-1}$ versus $\geqslant 30$ events $\cdot h^{-1}$; and $c$ ) percentage of night-time spent with oxygen saturation $<90 \%\left(t_{\text {sat } 90 \%}\right)<10.4 \%$ versus $\geqslant 10.4 \%$.

of malignancy during follow-up. However, stratified analysis showed that, in females only, sleep apnoea was associated with incident malignancy. This finding was independent of other known risk factors such as age, sex, BMI, smoking status, alcohol intake, socioeconomic status and HbA1c as a surrogate for diabetes severity. Females had a 3\% increased risk per unit increase of AHI and HR 4.2 for incident malignancy in case of severe sleep apnoea. There was no increased risk of malignancy with any sleep apnoea parameter in males. The incidence rate of malignancy was $1.9 \%$ per year compared to $1.1 \%$ in the German general population, including $\sim 7-8 \%$ of patients with T2D [37, 38].

This is the first study to investigate the association of sleep apnoea and the incidence of malignancy among T2D patients. Thus, results are compared to both sleep clinic and community cohorts with a proportion of T2D patients ranging between $3 \%$ and $22 \%$ (table 5).

In the present study, severity of sleep apnoea was not associated with the incidence of malignancy when males and females were combined. This result is consistent with two clinical cohort studies [10, 41]. In contrast to the present study, CAmpos-Rodriguez et al. [9] found that nocturnal hypoxaemia $\left(t_{\text {sat } 90 \%}>12 \%\right)$ was significantly associated with an increased risk of tumour incidence in a retrospective clinical cohort study on patients with suspected obstructive sleep apnoea (OSA). Several aspects of our study differ from the CAmpos-Rodriguez et al. study: first, CAmpos-Rodriguez et al. [9] did not indicate interaction terms, so it remains unclear whether the detected association was significantly different between males and females. Second, there are differences in the sample composition: the present study focused on patients with T2D, while Campos-Rodriguez et al. [9] included all patients from a sleep clinic with a focus on symptomatic patients documented by the high proportion of PAP treatment (57.9\%). Third, the DIACORE study found 
a)

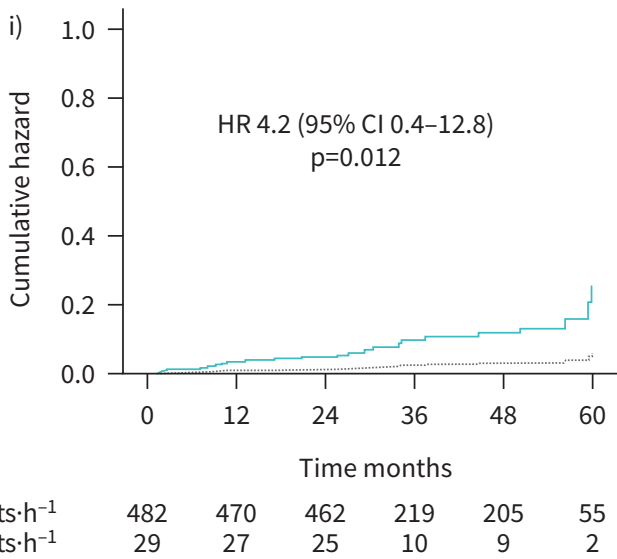

b)

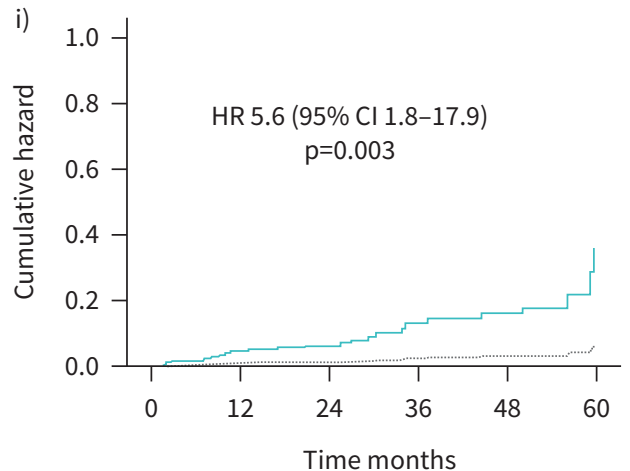

c)

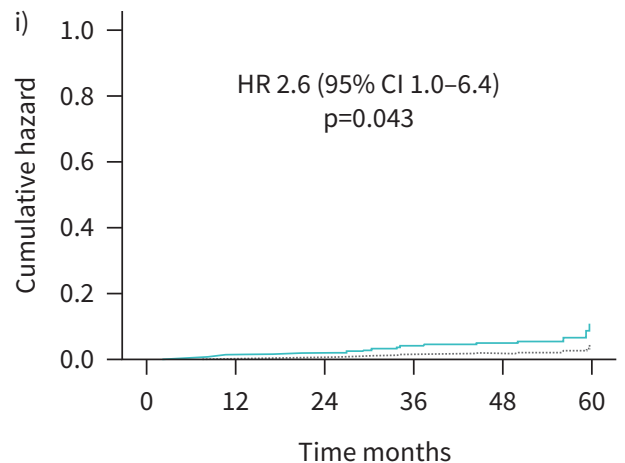

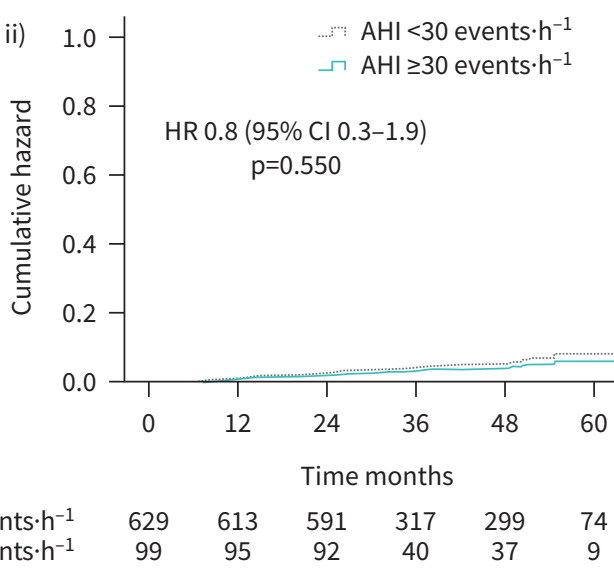
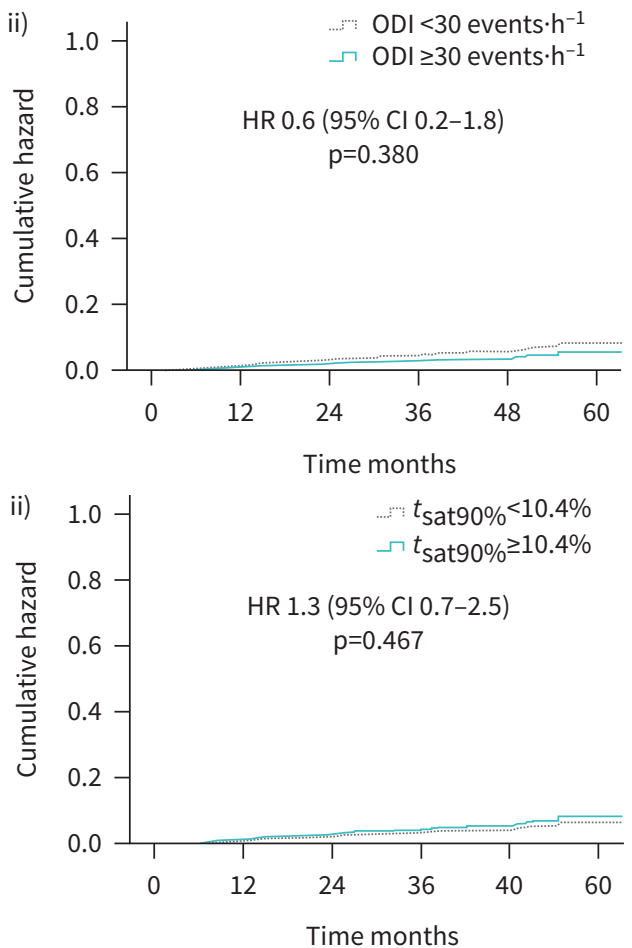

FIGURE 3 Cumulative adjusted hazard for incident malignancy in i) 511 females and ii) 728 males with a) apnoea-hypopnoea index (AHI) $<30$ events. $h^{-1}$ versus $\geqslant 30$ events $\cdot h^{-1}$; b) oxygen desaturation index (ODI) $<30$ events $\cdot h^{-1}$ versus $\geqslant 30$ events $\cdot h^{-1}$; and $\mathrm{c}$ ) percentage of night-time spent with oxygen saturation $<90 \%\left(t_{\text {sat } 90 \%}\right)<10.4 \%$ versus $\geqslant 10.4 \%$.

significant associations between sleep apnoea and incident malignancy in females for event-driven measures (AHI, ODI) as well as cyclic and continuous nocturnal hypoxaemia ( $\left.t_{\text {sat } 90 \%}\right)$, while CAmpos-Rodriguez et al. [9] only found an association for nocturnal hypoxaemia. Although patients with daytime respiratory failure were excluded in the study of CAmPOS-RoDRIGUEz et al. [9], the aetiology of nocturnal hypoxaemia remained unclear. In contrast to OSA, for example, obesity and pulmonary disease cannot be ruled out. In addition, the ODI, a specific marker of intermittent hypoxaemia to rule out effects from continuous hypoxaemia, was not available [9].

In the present study, $t_{\text {sat90\% }}$ showed a trend in the total sample (HR 1.59, 95\% CI 0.94-2.68; $\mathrm{p}=0.085$ ), suggesting a similarity with the CAMPOS-RODRIgUEz et al. [9] study. However, this was not statistically significant and possibly due to limited power. In addition, females showed an increased risk for higher

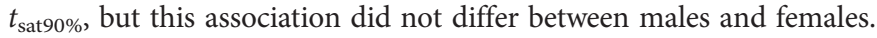

In a recent cross-sectional analysis of the European Sleep Apnea Database (ESADA) including 19556 patients, cancer prevalence was higher in females with sleep apnoea and nocturnal hypoxaemia, but not in males [42]. The only prospective cohort study investigating the association between sleep apnoea and cancer incidence, the community sample Busselton Health Study Cohort [39], with 390 individuals and 
TABLE 5 Association of sleep apnoea and incidence ${ }^{\#}$ of malignancy, comparison of existing studies

\begin{tabular}{cccccccc}
$\begin{array}{c}\text { First author } \\
\text { (year) [ref.] }\end{array}$ & $\begin{array}{c}\text { Population } \\
\mathrm{n}(\% \\
\text { female) }\end{array}$ & T2D \% & Study design & $\begin{array}{c}\text { Follow-up } \\
\text { years }\end{array}$ & $\begin{array}{c}\text { Sleep } \\
\text { apnoea } \\
\text { diagnosis }\end{array}$ & $\begin{array}{c}\text { Main } \\
\text { outcomes }\end{array}$ & Main findings \\
\hline
\end{tabular}

\section{Sleep apnoea \\ diagnosis with \\ PSG or PG}

Prospective

DRIENDL

12020;

1239

(41)

100

Prospective

cohort study

studyl

MaRSHALL

390

(2014) [39]

Prospective

cohort study

Retrospective

Justeau

(2020) [40]

8748

15

Retrospective

cohort study,

multicentre

CAMPOS-

4910

$n / s$

Retrospective

RODRIGUEZ

(2013) [9]

multicentre

BRENNER

5243

(2019) [10]

(26)

$\mathrm{n} / \mathrm{s}$

Retrospective

cohort study

5.9

PSG

PSG $(32 \%)$
PG $(68 \%)$

Cancer

incidence

( $n=261$ )

Cancer
incidence
(n=718)

Association

between

nocturnal

hypoxaemia

( $t_{\text {sat } 90 \%}>13 \%$ )

and cancer

incidence

Association

between severe

OSA $t_{\text {sat } 90 \%}$

$>12 \%$ ) and

cancer

incidence,

limited to male patients

$<65$ years

Association

Cancer

incidence

( $n=265$ )

$>57$ events $\cdot h^{-1}$

and cancer

incidence for

patients

$<45$ years

KENDZERSKA

10149

(2014) [41]

(38)

Retrospective

7.8

PSG

Cancer

incidence

cohort study,
multicentre

Cross-sectional

Pataka (2019)

[42]

19556

$\mathrm{n} / \mathrm{s}$

Cross-sectional

analysis,

multicentre

No association

between OSA

and cancer

incidence

PSG, PG

Cancer

prevalence

( $n=388$ )

Association

between

cancer

prevalence and

OSA and

nocturnal

hypoxaemia in

females

Use of $P G$

Small

population

Lack of control

of some

cancer risk

factors

Lack of

information on

PAP therapy

Lack of control of some

cancer risk

factors

Partial use of

PG

Lack of control of some

cancer risk

factors

Major use of $P G$

Lack of control of some

cancer risk factors

Lack of

information on

PAP therapy

Lack of control of some

cancer risk

factors

Lack of

information on

PAP therapy 


\section{TABLE 5 Continued}

\begin{tabular}{|c|c|c|c|c|c|c|c|c|}
\hline $\begin{array}{l}\text { First author } \\
\text { (year) [ref.] }\end{array}$ & $\begin{array}{c}\text { Population } \\
\mathrm{n}(\% \\
\text { female) }\end{array}$ & T2D \% & Study design & $\begin{array}{l}\text { Follow-up } \\
\text { years }\end{array}$ & $\begin{array}{c}\text { Sleep } \\
\text { apnoea } \\
\text { diagnosis }\end{array}$ & $\begin{array}{c}\text { Main } \\
\text { outcomes }\end{array}$ & Main findings & $\begin{array}{c}\text { Key } \\
\text { limitations }\end{array}$ \\
\hline $\begin{array}{l}\text { SHANTHA } \\
\text { (2015) [21] }\end{array}$ & $\begin{array}{c}112228 \\
(26-100)\end{array}$ & $4-22$ & $\begin{array}{l}\text { Meta-analysis, } \\
\text { five studies }\end{array}$ & $4.5-20$ & PSG, PG & $\begin{array}{l}\text { Cancer } \\
\text { incidence } \\
\text { (n=864) }\end{array}$ & $\begin{array}{l}\text { Patients with } \\
\text { SDB had a } \\
\text { nearly } 50 \% \\
\text { greater overall } \\
\text { cancer risk } \\
\text { compared with } \\
\text { patients } \\
\text { without SDB }\end{array}$ & \\
\hline $\begin{array}{l}\text { ZHANG (2017) } \\
\text { [22] }\end{array}$ & $\begin{array}{c}86460 \\
(26-38)\end{array}$ & $\mathrm{n} / \mathrm{s}$ & $\begin{array}{l}\text { Meta-analysis, } \\
\text { six studies }\end{array}$ & $4.5-20$ & PSG, PG & $\begin{array}{c}\text { Cancer } \\
\text { incidence } \\
\text { (n=965) }\end{array}$ & $\begin{array}{l}\text { OSA was not } \\
\text { independently } \\
\text { associated with } \\
\text { cancer } \\
\text { incidence }\end{array}$ & \\
\hline $\begin{array}{l}\text { CHRISTENSEN } \\
\text { (2013) [43] }\end{array}$ & $\begin{array}{l}8783 \\
(55)\end{array}$ & $\mathrm{n} / \mathrm{s}$ & $\begin{array}{l}\text { Prospective } \\
\text { cohort study }\end{array}$ & 13 & $\begin{array}{l}\text { Symptoms } \\
\text { of OSA }\end{array}$ & $\begin{array}{l}\text { Cancer } \\
\text { incidence } \\
\text { (n=1985) }\end{array}$ & $\begin{array}{l}\text { No association } \\
\text { between } \\
\text { symptoms of } \\
\text { OSA and } \\
\text { cancer } \\
\text { incidence }\end{array}$ & $\begin{array}{l}\text { OSA diagnosis } \\
\text { based on } \\
\text { symptoms } \\
\text { Lack of } \\
\text { information on } \\
\text { PAP therapy }\end{array}$ \\
\hline \multicolumn{9}{|l|}{ Retrospective } \\
\hline $\begin{array}{l}\text { GozAL (2016) } \\
\quad[11]\end{array}$ & $\begin{array}{l}5.6 \text { million } \\
(50)\end{array}$ & $\begin{array}{c}14 \text { in } \\
\text { OSA-group }\end{array}$ & $\begin{array}{l}\text { Retrospective } \\
\text { cohort study }\end{array}$ & $3.2-3.9$ & $\begin{array}{l}\text { According } \\
\text { to } \\
\text { ICD-9-CM }\end{array}$ & $\begin{array}{c}\text { Cancer } \\
\text { incidence } \\
\text { (n=167022) }\end{array}$ & $\begin{array}{l}\text { Elevated risk } \\
\text { for malignant } \\
\text { melanoma and } \\
\text { kidney and } \\
\text { pancreatic } \\
\text { cancer for } \\
\text { patients with } \\
\text { OSA } \\
\text { Lower risk for } \\
\text { colorectal, } \\
\text { breast and } \\
\text { prostate cancer } \\
\text { for patients } \\
\text { with OSA }\end{array}$ & $\begin{array}{l}\text { Potential bias } \\
\text { by use of } \\
\text { administrative } \\
\text { claims } \\
\text { database } \\
\text { Lack of control } \\
\text { of some } \\
\text { cancer risk } \\
\text { factors }\end{array}$ \\
\hline $\begin{array}{l}\text { SilLAh (2018) } \\
\text { [12] }\end{array}$ & $\begin{array}{c}34402 \\
(43)\end{array}$ & $\mathrm{n} / \mathrm{s}$ & $\begin{array}{l}\text { Retrospective } \\
\text { cohort study }\end{array}$ & 5.3 & $\begin{array}{l}\text { According } \\
\text { to } \\
\text { ICD-9-CM }\end{array}$ & $\begin{array}{c}\text { Cancer } \\
\text { incidence } \\
\text { (n=1575) }\end{array}$ & $\begin{array}{l}\text { Elevated risk } \\
\text { for malignant } \\
\text { melanoma and } \\
\text { kidney, uterine } \\
\text { and breast } \\
\text { cancer for } \\
\text { patients with } \\
\text { OSA } \\
\text { Lower risk for } \\
\text { colorectal and } \\
\text { lung cancer for } \\
\text { patients with } \\
\text { OSA }\end{array}$ & $\begin{array}{l}\text { Lack of control } \\
\text { of some } \\
\text { cancer risk } \\
\text { factors } \\
\text { Lack of } \\
\text { information on } \\
\text { PAP therapy }\end{array}$ \\
\hline
\end{tabular}

T2D: type 2 diabetes mellitus; PSG: polysomnography; PG: polygraphy; OSA: obstructive sleep apnoea; ICD-9-CM: International Classification of Diseases, 9th Revision, Clinical Modification; AHI: apnoea-hypopnoea index; RDI: respiratory disturbance index; n/s: not specified; PAP:

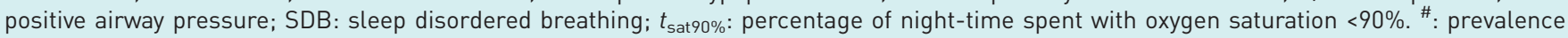
shown for PATAKA et al. [42]. 
125 events observed during a follow-up time of 20 years, showed that participants with moderate to severe sleep apnoea had a 2.5 -fold elevated risk of an incident malignancy, but there were no differences between males and females. However, hazard ratios for females were elevated but not statistically significant, probably because of a small sample size, as the analysis had only five females in the moderate-to-severe OSA group [39].

Even meta-analyses found inconsistent results when investigating the association between sleep apnoea and the incidence of malignancy. Whereas Shantha et al. [21] found a 50\% greater overall cancer risk compared to patients without sleep apnoea, ZHANG et al. [22] found that sleep apnoea was not associated with incidence of malignancy (table 5). Other studies examining overall malignancy and site-specific cancer observed that sleep apnoea was only associated with specific cancer types such as malignant melanoma, kidney, pancreatic, uterine and breast cancer [11, 12] (table 5). Reasons for the inconsistency of these studies could be limited study power, retrospective design, poor control of cancer risk factors and potential bias by use of administrative claims database (table 5).

Different pathophysiological mechanisms were suggested to explain the association between sleep apnoea and incident malignancy, such as intermittent hypoxaemia and sleep fragmentation resulting in oxidative stress, systemic inflammation and immunodeficiency $[16,44]$. These mechanisms can contribute to changes in tumour biology, accelerated tumour growth and progression of existing tumours including metastasis [16]. We found an association of sleep apnoea and incident malignancy only in females, but not in males. One reason could be that females are more likely to have regular physician's visits and therefore are more likely to receive a malignancy diagnosis $[45,46]$.

In our study, skin tumours were the most common malignancy ( $\mathrm{n}=20,25 \%$ of all neoplasms). This observation differs from the expected distribution of tumours, in which prostate, breast, lung and colorectal cancer would be the most frequent tumours [37]. Studies found a hypoxic microenvironment of the skin contributing to melanocyte transformation [47] and a significantly higher incidence of melanomas in patients with sleep apnoea $[11,12]$. However, we lacked statistical power to examine this association. Sensitivity analyses of the association between measures of sleep apnoea and incidence of malignancy without nonmelanotic skin cancers show similarly increased hazard ratios in females (supplementary tables S1 and S2).

There is evidence that PAP treatment may have a moderating role in patients with sleep apnoea and in neoplasm-related pathways [48-50]. In the present study, there was no difference in malignancy incidence between patients with and without PAP therapy among patients with at least mild sleep apnoea, nor among patients with moderate-to-severe sleep apnoea. This should not be interpreted as a lack of efficacy in PAP therapy, as the number of events in the PAP therapy group was very low ( $\mathrm{n}=5$ in both analyses). Furthermore, because we consider sleep apnoea to be a chronic disease with intermittent hypoxaemia and other consequences of the disorder likely to have been present for several years before, recent treatment would probably not immediately affect the outcome.

Strengths of our study include the prospective study design and detailed phenotyping at baseline, which ensures wide and complete information about lifestyle and socioeconomic factors of the participants, enabling adjustment for the primary known cancer-related risk factors. Furthermore, we only validated cancer diagnoses when the self-reported diagnosis could be validated by a medical report.

The present study has the following limitations and thus cannot rule out an association of sleep apnoea and incidence of malignancy. First, we used a portable respiratory device to diagnose sleep apnoea. Even though the usage of a home sleep apnoea monitoring device is well established and validated for assessment of sleep apnoea $[35,51]$, due to the missing chest band, we could not distinguish between obstructive and central sleep apnoea. As a result, it is possible that the association we found is only valid for one of the two forms of sleep apnoea. Nonetheless, as we consider OSA to be the main pathophysiology linking sleep apnoea and incident malignancy, not excluding central sleep apnoea from the analysis would most likely confer a conservative bias towards the null, i.e. underestimate the association between sleep apnoea and the incidence of malignancy. Moreover, in previous studies of patients with T2D, 99\% of the sleep apnoea was obstructive [26, 27]. Furthermore, inaccurate measurement of the AHI could result from the use of ApneaLink as a monitoring device, which could decrease the potential association between sleep apnoea and incidence of malignancy. Second, we lacked the statistical power to examine site-specific malignancies. Thus, we cannot rule out an association between sleep apnoea and site-specific malignancies such as malignant melanoma [11, 12]. Third, the median follow-up time of the study is $\sim 2.7$ years, which is a rather short period of time for evaluating the incidence of malignancies and could decrease the potential association between sleep apnoea and incidence of malignancy. However, we detected an overall cumulative tumour incidence of $6.4 \%$, which is largely comparable to previous studies investigating the association between sleep apnoea and incident 
malignancy $[9,10,41]$. It cannot be ruled out that some malignancies were already present at baseline, but not yet diagnosed. Fourth, the diagnosis of a malignancy was only possible when reported by the participants in follow-up visits, after which a medical report was obtained to validate the self-reported diagnosis, potentially introducing bias. Fifth, investigation of patients with T2D could lead to referral bias. Sixth, the use of Bonferroni-corrected p-values for the female and age-stratified analyses constitutes a conservative statistical approach. Last, similar to most previous studies evaluating the association of sleep apnoea and cancer, the present study was not prospectively designed for this research question. Prospective studies on this topic are warranted.

In summary, there was no association between sleep apnoea and incident malignancy in this sample of patients with T2D. However, stratified analysis revealed a significant association of sleep apnoea with incident malignancy in females, but not in males. These findings emphasise the necessity to further investigate whether there are groups at higher risk for an incident malignancy associated with sleep apnoea and how T2D influences this association. Therefore, further research including longitudinal analyses and intervention studies is required to enhance the understanding of the underlying pathophysiological mechanisms of sleep apnoea on the incidence of malignancies.

Acknowledgements: We thank all participating patients of the DIACORE study. We thank the physicians and health insurance companies supporting the DIACORE study: Axel Andreae, Gerhard Haas, Sabine Haas, Jochen Manz, Johann Nusser, Günther Kreisel, Gerhard Bawidamann, Frederik Mader, Susanne Kißkalt, Johann Hartl, Thomas Segiet, Christiane Gleixner and Christian Scholz (Regensburg, Germany), Monika Schober (Allgemeine Ortskrankenkasse Bayern), Cornelia Heinrich (Allgemeine Ortskrankenkasse Bayern), Thomas Bohnhoff (Techniker Krankenkasse), Thomas Heilmann (Techniker Krankenkasse), Stefan Stern (Allgemeine Ortskrankenkasse Bayern), Andreas Utz (Allgemeine Ortskrankenkasse Bayern), Georg Zellner (Deutsche Angestellten Krankenkasse), Werner Ettl (Barmer-GEK), Thomas Buck (Barmer-GEK), Rainer Bleek (IKK classic) and Ulrich Blaudzun (IKK classic). We further thank the study nurses for their excellent work in performing the study visits: Simone Neumeier, Sarah Hufnagel, Isabell Haller, Petra Jackermeier, Sabrina Obermüller, Christiane Ried, Ulrike Hanauer, Bärbel Sendtner and Natalia Riewe-Kerow (Centre of Clinical Studies, University Hospital Regensburg, Regensburg). Konstantin Dumann and Britta Hörmann (PhD students, University Hospital Regensburg) are thanked for their work in performing the study visits. We thank Helge Knüttel for his exceptional support in literature research.

Author contributions: S. Driendl, M. Arzt and S. Stadler were involved in the conception, hypotheses delineation and design of the study, the analysis and interpretation of such information, writing the article, and in its revision prior to submission. C.A. Böger, I.M. Heid and B. Jung are the principal investigators of the DIACORE study, and were involved in the design of this substudy, the acquisition and interpretation of the data, and the critical revision of the article prior to submission. C.S. Zimmerman was involved in the acquisition and interpretation of the data, and the critical revision of the article prior to submission. S. Haferkamp was involved in the interpretation of the data and the critical revision of the article prior to submission. F. Zeman was involved in statistical data analysis. All authors read and approved the final manuscript. S. Stadler is the guarantor of this work and, as such, had full access to all data of the study, and takes responsibility for the integrity of the data and the accuracy of the data analysis. S. Driendl and M. Artz contributed equally to this work.

Conflict of interest: S. Driendl has nothing to disclose. M. Arzt reports grants from the Else-Kröner Fresenius Foundation and the Resmed Foundation, grants and personal fees from Philips Respironics and ResMed, and personal fees from Boehringer Ingelheim, Novartis, Brestotec and NRI, outside the submitted work. C.S. Zimmermann has nothing to disclose. B. Jung has nothing to disclose. T. Pukrop has nothing to disclose. C.A. Böger reports grants from KfH Stiftung Präventivmedizin e.V., the Else Kröner-Fresenius-Stiftung and the Dr Robert Pfleger Stuftung during the conduct of the study. S. Haferkamp has nothing to disclose. F. Zeman has nothing to disclose. I.M. Heid has nothing to disclose. S. Stadler has nothing to disclose.

Support statement: The DIACORE study has been funded by the KfH Stiftung Präventivmedizin e.V., the Else-Kröner-Fresenius-Stiftung and the Dr Robert-Pflieger-Stiftung. The DIACORE-SDB substudy has been funded by ResMed (Martinsried, Germany).

\section{References}

1 Heinzer R, Vat S, Marques-Vidal P, et al. Prevalence of sleep-disordered breathing in the general population: the HypnoLaus study. Lancet Respir Med 2015; 3: 310-318.

2 Peppard PE, Young T, Barnet $\mathrm{JH}$, et al. Increased prevalence of sleep disordered breathing in adults. Am J Epidemiol 2013; 177: 1006-1014.

3 Jordan AS, McSharry DG, Malhotra A. Adult obstructive sleep apnoea. Lancet 2014; 383: 736-747.

4 Drager LF, McEvoy RD, Barbe F, et al. Sleep apnea and cardiovascular disease: lessons from recent trials and need for team science. Circulation 2017; 136: 1840-1850.

5 Malhotra A, White DP. Obstructive sleep apnoea. Lancet 2002; 360: 237-245.

6 Somers VK, Dyken ME, Clary MP, et al. Sympathetic neural mechanisms in obstructive sleep apnea. J Clin Invest 1995; 96: 1897-1904.

7 Yamauchi M, Nakano H, Maekawa J, et al. Oxidative stress in obstructive sleep apnea. Chest 2005; 127: 1674-1679.

8 McNicholas WT. Obstructive sleep apnea and inflammation. Prog Cardiovasc Dis 2009; 51: 392-399.

9 Campos-Rodriguez F, Martinez-Garcia MA, Martinez M, et al. Association between obstructive sleep apnea and cancer incidence in a large multicenter Spanish cohort. Am J Respir Crit Care Med 2013; 187: 99-105. 
10 Brenner R, Kivity S, Peker M, et al. Increased risk for cancer in young patients with severe obstructive sleep apnea. Respiration 2019; 97: 15-23.

11 Gozal D, Ham SA, Mokhlesi B. Sleep apnea and cancer: analysis of a nationwide population sample. Sleep 2016; 39: 1493-1500.

12 Sillah A, Watson NF, Schwartz SM, et al. Sleep apnea and subsequent cancer incidence. Cancer Causes Control 2018; 29: 987-994.

13 Toffoli S, Michiels C. Intermittent hypoxia is a key regulator of cancer cell and endothelial cell interplay in tumours. FEBS J 2008; 275: 2991-3002.

14 Liu Y, Song X, Wang X, et al. Effect of chronic intermittent hypoxia on biological behavior and hypoxia-associated gene expression in lung cancer cells. J Cell Biochem 2010; 111: 554-563.

15 Muz B, de la Puente P, Azab F, et al. The role of hypoxia in cancer progression, angiogenesis, metastasis, and resistance to therapy. Hypoxia 2015; 3: 83-92.

16 Almendros I, Wang Y, Gozal D. The polymorphic and contradictory aspects of intermittent hypoxia. Am J Physio Lung Cell Mol Physiol 2014; 307: L129-L140.

17 Almendros I, Montserrat JM, Ramírez J, et al. Intermittent hypoxia enhances cancer progression in a mouse model of sleep apnoea. Eur Respir J 2012; 39: 215-217.

18 Perini S, Martinez D, Montanari CC, et al. Enhanced expression of melanoma progression markers in mouse model of sleep apnea. Rev Port Pneumol 2016; 22: 209-213.

19 Rofstad EK, Gaustad J-V, Egeland TAM, et al. Tumors exposed to acute cyclic hypoxic stress show enhanced angiogenesis, perfusion and metastatic dissemination. Int J Cancer 2010; 127: 1535-1546.

20 Nieto FJ, Peppard PE, Young T, et al. Sleep disordered breathing and cancer mortality: results from the Wisconsin Sleep Cohort Study. Am J Respir Crit Care Med 2012; 186: 190-194.

21 Shantha GPS, Kumar AA, Cheskin LJ, et al. Association between sleep-disordered breathing, obstructive sleep apnea, and cancer incidence: a systematic review and meta-analysis. Sleep Med 2015; 16: 1289-1294.

22 Zhang X-B, Peng L-H, Lyu Z, et al. Obstructive sleep apnoea and the incidence and mortality of cancer: a meta-analysis. Eur J Cancer Care 2017; 26: e12427.

23 Danaei G, Finucane MM, Lu Y, et al. National, regional, and global trends in fasting plasma glucose and diabetes prevalence since 1980: systematic analysis of health examination surveys and epidemiological studies with 370 country-years and 2.7 million participants. Lancet 2011; 378: 31-40.

24 Wild S, Roglic G, Green A, et al. Global prevalence of diabetes: estimates for the year 2000 and projections for 2030. Diabetes Care 2004; 27: 1047-1053.

25 Aurora RN, Punjabi NM. Obstructive sleep apnoea and type 2 diabetes mellitus: a bidirectional association. Lancet Respir Med 2013; 1: 329-338.

26 Laaban J-P, Daenen S, Léger D, et al. Prevalence and predictive factors of sleep apnoea syndrome in type 2 diabetic patients. Diabetes Metab 2009; 35: 372-377.

27 Foster GD, Sanders MH, Millman R, et al. Obstructive sleep apnea among obese patients with type 2 diabetes. Diabetes Care 2009; 32: 1017-1019.

28 Kroner T, Arzt M, Rheinberger M, et al. Sex differences in the prevalence and modulators of sleep disordered breathing in outpatients with type 2 diabetes. J Diabetes Res 2018; 2018: 7617524.

29 Resnick HE, Redline S, Shahar E, et al. Diabetes and sleep disturbances: findings from the Sleep Heart Health Study. Diabetes Care 2003; 26: 702-709.

30 Gallagher EJ, LeRoith D. Obesity and diabetes: the increased risk of cancer and cancer-related mortality. Physiol Rev 2015; 95: 727-748.

31 Stadler S, Zimmermann T, Franke F, et al. Association of sleep-disordered breathing with diabetes-associated kidney disease. Ann Med 2017; 49: 487-495.

32 Dörhöfer L, Lammert A, Krane V, et al. Study design of DIACORE (DIAbetes COhoRtE) - a cohort study of patients with diabetes mellitus type 2. BMC Med Genet 2013; 14: 25.

33 Lampert T, Kroll LE, Müters S, et al. Messung des sozioökonomischen Status in der Studie "Gesundheit in Deutschland aktuell" (GEDA). [Measurement of the socioeconomic status within the German Health Update 2009 (GEDA)]. Bundesgesundheitsblatt Gesundheitsforschung Gesundheitsschutz 2013; 56: 131-143.

34 Chen $\mathrm{H}$, Lowe AA, Bai Y, et al. Evaluation of a portable recording device (ApneaLink) for case selection of obstructive sleep Apnea. Sleep Breath 2009; 13: 213-219.

35 Erman MK, Stewart D, Einhorn D, et al. Validation of the ApneaLink for the screening of sleep apnea: a novel and simple single-channel recording device. J Clin Sleep Med 2007; 3: 387-392.

36 Berry RB, Budhiraja R, Gottlieb DJ, et al. Rules for scoring respiratory events in sleep: update of the 2007 AASM Manual for the Scoring of Sleep and Associated Events. Deliberations of the Sleep Apnea Definitions Task Force of the American Academy of Sleep Medicine. J Clin Sleep Med 2012; 8: 597-619.

37 Barnes B, Kraywinkel K, Nowossadeck E, et al. Bericht zum Krebsgeschehen in Deutschland 2016. [Report of the Occurrence of Cancer in Germany]. Berlin, Robert Koch Institute, 2016.

38 Deutsche Diabetes Gesellschaft (DDG), diabetesDE - Deutsche Diabetes-Hilfe. Deutscher Gesundheitsbericht Diabetes 2016: Die Bestandsaufnahme [German Health Report Diabetes]. Mainz, Kirchheim, 2016.

39 Marshall NS, Wong KKH, Cullen SRJ, et al. Sleep apnea and 20-year follow-up for all-cause mortality, stroke, and cancer incidence and mortality in the Busselton Health Study cohort. J Clin Sleep Med 2014; 10: 355-362.

40 Justeau $\mathrm{G}$, Gervès-Pinquié $\mathrm{C}$, Le Vaillant $\mathrm{M}$, et al. Association between nocturnal hypoxemia and cancer incidence in patients investigated for OSA: data from a large multicenter French cohort. Chest 2020; 158: 2610-2620.

41 Kendzerska T, Leung RS, Hawker G, et al. Obstructive sleep apnea and the prevalence and incidence of cancer. CMAJ 2014; 186: 985-992.

42 Pataka A, Bonsignore MR, Ryan S, et al. Cancer prevalence is increased in females with sleep apnoea: data from the ESADA study. Eur Respir J 2019; 53: 190091.

43 Christensen AS, Clark A, Salo P, et al. Symptoms of sleep disordered breathing and risk of cancer: a prospective cohort study. Sleep 2013; 36: 1429-1435.

44 Lévy P, Pépin J-L, Arnaud C, et al. Intermittent hypoxia and sleep-disordered breathing: current concepts and perspectives. Eur Respir J 2008; 32: 1082-1095. 
45 Shalev V, Chodick G, Heymann AD, et al. Gender differences in healthcare utilization and medical indicators among patients with diabetes. Public Health 2005; 119: 45-49.

46 Ladwig KH, Marten-Mittag B, Formanek B, et al. Gender differences of symptom reporting and medical health care utilization in the German population. Eur J Epidemiol 2000; 16: 511-518.

47 Bedogni B, Welford SM, Cassarino DS, et al. The hypoxic microenvironment of the skin contributes to Akt-mediated melanocyte transformation. Cancer Cell 2005; 8: 443-454.

48 Gharib SA, Seiger AN, Hayes AL, et al. Treatment of obstructive sleep apnea alters cancer-associated transcriptional signatures in circulating leukocytes. Sleep 2014; 37: 709-714, 714A-714T.

49 Weaver TE, Mancini C, Maislin G, et al. Continuous positive airway pressure treatment of sleepy patients with milder obstructive sleep apnea: results of the CPAP Apnea Trial North American Program (CATNAP) randomised clinical trial. Am J Respir Crit Care Med 2012; 186: 677-683.

50 Krachman S, Swift I, Vega ME. Comparison of positional therapy to CPAP in patients with positional obstructive sleep apnea. In: de Vries N, Ravesloot M, van Maanen JP, eds. Positional Therapy in Obstructive Sleep Apnea. Cham, Springer International Publishing, 2015.

51 Arzt M, Woehrle H, Oldenburg O, et al. Prevalence and predictors of sleep disordered breathing in patients with stable chronic heart failure: the SchlaHF Registry. JACC Heart Fail 2016; 4: 116-125. 